\title{
Advanced Squamous Cell Carcinoma
}

National Cancer Institute

\section{Source}

National Cancer Institute. Advanced Squamous Cell Carcinoma. NCI Thesaurus. Code C162653.

Squamous cell carcinoma that has spread extensively to other anatomic sites or is no longer responding to treatment. 